\title{
Incidence of Idiopathic Intracranial Hypertension in Fife
}

Colin Goudie

Ophthalmology Registrar, Princess Alexandra Eye Pavilion, Edinburgh

Jennifer Burr

Reader in Ophthalmology, St Andrews University

Andrew Blaikie

Consultant Ophthalmologist, NHS Fife and Honorary Senior Lecturer, Global Health Implementation Programme, University of St Andrews

Corresponding author -

Colin Goudie

Princess Alexandra Eye Pavilion, Chalmers, Street, Edinburgh

crgoudie@gmail.com

Word count - 2089 


\section{Abstract \\ $\underline{\text { Background and Aims }}$}

Idiopathic intracranial hypertension (IIH) is a clinical syndrome of intracranial hypertension with normal cerebrospinal fluid in the absence of a mass lesion or hydrocephalus on brain imaging. Headache is the most common symptom of $\mathrm{IIH}$, and about $10-15 \%$ of patients suffer irreversible visual impairment. Previous estimates of the annual incidence of IIH vary world-wide from 0.03-2.2 per 100,000. The major risk factor implicated in IIH is body mass. Scotland has one of the worst records for obesity in the developed world and the prevalence of obesity in Fife is significantly higher than the Scottish average. Our aim was to record the incidence of IIH in NHS Fife over a one year period.

$\underline{\text { Methods and Results }}$

Prospective study including every patient that was seen in the ophthalmology department in NHS Fife with a new diagnosis of IIH over a one year period.

Thirteen patients were seen with a new diagnosis of IIH from August 2013 to July 2014 giving an incidence of 3.56 per 100 000. Headache was the most common presenting symptom. Three patients were asymptomatic but were noted to have swollen optic discs during a routine sight test. One patient complained of visual symptoms. All patients were overweight. The mean BMI was 36 (range 28-49)

\section{$\underline{\text { Conclusion }}$}

The incidence of IIH in NHS Fife was between 2 and 4 times higher than previous estimates in the literature. This is probably due to a high level of obesity in Fife. Scotland is in the midst of an obesity epidemic and if this continues we may see increasing levels of IIH nationally with associated increasing incidence of visual impairment in young adults. 
Keywords - IIH, obesity, Fife

\section{Introduction}

Idiopathic intracranial hypertension (IIH) is a clinical syndrome of intracranial hypertension with normal cerebrospinal fluid (CSF) in the absence of a mass lesion or hydrocephalus on brain imaging. Its aetiology is unknown, and in adults it classically affects young women of childbearing age. Diagnosis is made based on the Modified Dandy Criteria $^{1}$ (table 1) and the clinical features, risk factors and natural history are well described in the literature ${ }^{2}$. Previous estimates of the annual incidence of IIH vary from $0.03-2.2$ per $100,000^{22}$, apparently depending on geographical location and population demography. The estimated incidence in the 'at risk' population (women of childbearing age that are obese) is $3.5 / 100,000^{22}$. The most common symptoms of IIH are headache and transient visual loss. In the majority of cases, IIH is treatable, without impairment of vision in the long term. However, a group of patients exist who develop permanent visual loss, which can be rapidly progressive and devastating ${ }^{3,4}$. The major risk factor implicated in IIH is body mass ${ }^{5-8}$. The majority of patients with IIH are obese (defined as having a body mass index (BMI) of over 30) and there is also a link between recent weight gain and IIH. Scotland has one of the worst records for obesity in the developed world and the prevalence of obesity in 2012 was estimated at $27 \%$ in the adult population, whilst $64.3 \%$ of adults were obese or overweight (BMI 25-29.9) ${ }^{9}$. The prevalence of obesity in Fife is higher than the national average and is the fifth highest in all of the health boards in Scotland ${ }^{10}$. We aimed to record the incidence of IIH in NHS Fife over a period of one year. The population served by NHS Fife is estimated at 365,000 . 


\section{Methods}

All new cases of IIH seen in the ophthalmology department in NHS Fife, at Queen Margaret Hospital and Victoria Hospital Kirkcaldy, were collected prospectively from August 2013 to July 2014 (1 year). Each diagnosis was made by a consultant ophthalmologist and a consultant neurologist. Demographic details and risk factors for each patient were recorded from their clinical notes. The study was run in accordance with the NHS Fife Quality Improvement Register.

\section{Results}

Thirteen new cases of IIH were seen in NHS Fife over the one year period giving an incidence of 3.56 per 100,000 patients. Twelve of these cases met all of the Modified Dandy Criteria (see figure 1). The other case was a patient on anti-coagulant therapy for a pulmonary embolus. She presented with intermittent visual disturbance before developing bilateral swollen optic discs, in keeping with IIH, a week later. Cranial imaging showed no abnormality, however lumbar puncture was not performed because of the risk of bleeding.

Twelve out of thirteen patients were female and the patients ranged from aged 17-50 (mean age 29). Presenting symptoms and details of the referrer were missing from the case notes of one patient, for whom there was also no mention of visual fields. Mean BMI was 36.7 (range 27-51). Six out of thirteen patients were current or exsmokers. Two patients were pregnant (21 and 28 weeks gestation). Headache was the major presenting symptom in 9 out of 12 patients. In those who had headaches one patient was also suffering from nausea and one patient complained of transient visual blurring. The other three patients were asymptomatic and had attended their optician 
for a routine sight test. Eleven out of thirteen patients were seen by ophthalmology within 1 day of referral.

At ophthalmology review twelve out of thirteen patients had a best corrected Snellen visual acuity of at least $6 / 6$ in both eyes (the other patient's vision was unchanged form their normal at 6/9 right and 6/18 left). None of our patients had a significant visual field deficit on presentation, although reliability was low in 3 tests. Twelve patients had optic disc swelling initially (asymmetry was noted in 4 patients) and one patient also had a disc haemorrhage. As mentioned above, the other patient had normal optic discs however was reviewed a week later because she was complaining of transient visual blurring. At this stage she had developed bilateral asymmetrical disc swelling.

All of the patients had no significant abnormality on cranial imaging (11 with CT head and venogram, 2 with MRI head and venogram) and mean lumbar puncture opening pressure was $35 \mathrm{cmCSF}$ (range 26-53). CSF composition was normal in all cases.

Ten patients were referred to ophthalmology by their optometrists, one by obstetrics and gynaecology one by their GP.

\section{Discussion}

Thirteen patients were diagnosed with IIH in Fife from July 2013 to August 2014 giving an incidence of 3.56 per 100,000 of the population. This figure is significantly higher than those previously quoted in the world literature (table 2).

With on-going improvements in complex neuroimaging the diagnostic criteria for IIH have undergone several modifications over the years. It is now widely accepted that diagnosis of IIH should be made based on the 'modified Dandy criteria' set out by 
Friedman and Jacobsen in $2002^{1}$. Despite these criteria, there can be pitfalls when diagnosing IIH (such as papilloedema vs pseudo-papilloedema). As such, the criteria guide a 'best fit' rather than a definitive diagnosis. Fotunatelely for the sake of this study, twelve out of thirteen of our patients met each of these criteria, whilst diagnosis in the other patient was made clinically as discussed above.

The pathogenesis of IIH remains unclear, however the link between IIH and female sex ${ }^{11-13}$, reproductive age and obesity is established. The evidence linking IIH and obesity is conclusive $\mathrm{e}^{5-8}$. Of the thirteen patients that we saw with a recorded BMI, ten (77\%) were obese (range $32-51)$ and the other three $(23 \%)$ were overweight (range 27-29). Mean BMI was 36.7. Previous studies have demonstrated rates of obesity $(\mathrm{BMI}>30)$ amongst patients with $\mathrm{IIH}$ to be as high as $71-91 \%{ }^{8,12,14}$. One study estimated the mean weight of patients with IIH to be $38 \%$ above their ideal body weight $^{11}$. There is also a link between recent weight gain and IIH, however we did not specifically record this in our patient group.

Obesity is a leading cause of death and disease and its global prevalence has more than doubled since 1980. The World Health Organisation has described this situation as an "epidemic" and estimates that over 500 million adults world wide are obese and 1.5 billion adults are either overweight or obese ${ }^{15}$. Fife has the $5^{\text {th }}$ highest prevalence of obesity out of the 14 NHS Healthboards in Scotland, a country where obesity rates have increased from $17.2 \%$ in 1995 to $25.6 \%$ in 2013 . It seems likely that the high prevalence of obesity in Fife is linked to the high incidence of IIH. Moreover, it is likely that other regions in Scotland, with similar levels of obesity, may have similarly high incidences of IIH. Further research may determine whether this is the case.

Headache is the most common symptom of IIH (present in 10/12 of our patients) affecting $68-98 \%$ of patients ${ }^{18}$. However it is visual impairment, caused by ischaemic 
damage to the optic nerve fibres, which are compressed during swelling, that is the main cause of morbidity. This can lead to irreversible sight loss. A British Ophthalmic Surveillance Unit (BOSU) study estimated that 1-2\% of patients with IIH are likely to go blind in a given year ${ }^{3}$, but blindness rates elsewhere have been reported as high as $10 \%{ }^{17}$. Population-based surveys indicate an overall rate of visual impairment between 10 and $20 \%^{12,17}$. Visual field abnormalities, picked up on automated perimetry, are one of the earliest indications of optic nerve damage, with reduction of contrast sensitivity, colour vision and visual acuity occurring later. It is important to note that the grade of visual field defect does not correlate with the degree of disc swelling. None of our patients' displayed signs of significant optic nerve damage on presentation. Other symptoms of IIH are usually reversible as intracranial pressure returns to normal. This includes diplopia, (present in one of our patients and caused by compression of the abducens nerve, as seen in raised intracranial pressure from other causes), 'whooshing' in the ear (present in one patient), nausea and vomiting and neck stiffness and photophobia (due to meningeal irritation).

Ten out of the thirteen patients in our study were referred to the hospital eye service by community optometrists. Three of these had attended their optometrist for a 'routine' sight test, with no visual symptoms or headache. In 2006, new General Ophthalmic Services (Scotland) arrangements were introduced, delivering universally free comprehensive community based eye care services for the people of Scotland. All optometry practices were required to meet a new minimum standard, resulting in improvements in equipment as well as clinical skills, with the ultimate aim of improving referrals to the hospital eye service. The new contract has led to a change in what is considered to be a 'routine sight test', with fundal photos, visual fields and 
fundoscopy becoming the norm. More thorough examination has led to a new group of asymptomatic patients being referred to the hospital eye service, of which optic disc, retinal and visual field abnormalities make up a large proportion ${ }^{16}$. We feel that this has resulted in increased numbers of patients being diagnosed with IIH despite being asymptomatic. These asymptomatic patients can be particularly difficult to manage and, with no clinical symptoms to guide management, often require more frequent follow-up.

There are a number of questions raised by the high incidence of IIH in Fife. Would our findings be consistent across the other health boards in Scotland? If the current trend continues, will clinic capacity cope with the number of appointments needed to provide adequate assessment and follow-up? Treatment of IIH is initially medical ${ }^{18}$, usually with oral acetazolamide, however those with acute severe visual loss, intractable headache or chronic progressive visual loss, not controlled by medical measures, require a surgical intervention to alter the flow of CSF. If successful, this will treat both papilloedema and headache, however complications are common and limit the effectiveness of these procedures ${ }^{19}$. It is well known that weight loss improves the course of IIH, causing resolution of symptoms and papilloedema ${ }^{20,21}$. Many patients struggle with this, prompting the question as to whether a more aggressive approach to weight loss, such as supervised dieting or bariatric surgery, should be made more readily available in patients with early signs of sight loss. Lastly, if the incidence of IIH continues to rise alongside the nation's BMI, will we see an increased incidence in visual impairment and blindness amongst young women, with associated significant social implications? 
The major limitations of our study might actually result in an underestimate of the incidence. Fife is an area in the East of Scotland with two main hospitals, Queen Margaret's Hospital, Dunfermline and Victoria Hospital, Kirkaldy. Much of the local population works in neighbouring cities such as Edinburgh, Dundee and Stirling, all of which have large hospitals in other health boards. As a result, patients may present to a hospital outwith Fife, which may lead to an underestimation of the incidence of $\mathrm{IIH}$ in our study. As mentioned earlier it is also likely that there is a population of unidentified, asymptomatic individuals with IIH in the community, and our study has no way of identifying these individuals. This may also lead to an underestimate of the true incidence of IIH in Fife. Incidence studies run on the assumption that all cases that are seen are reported to the investigators, which is not always the case. Fortunately, in NHS Fife, all patients with IIH are eventually seen by the same consultant ophthalmologist $(\mathrm{AB})$ and neurologist, who share these patients. It is therefore unlikely that any patients seen in NHS Fife during our study period were not reported.

Conversely, it is possible that our study overestimates the incidence of IIH: our study was conducted over a one year period and this may not be representative of a long term incidence. That being said, when weighing this possibility against the potential causes of an underestimate mentioned earlier it seems more likely that our results favour a lower value than the true incidence.

Our prospective study estimates the incidence of IIH in Fife as between 2 and 6 times higher than previously quoted in other UK studies. The most likely explanation for this high incidence is the high levels of obesity in Fife, but the improvement in fundal 
examinations heralded by the new national optometry contract may also contribute. Scotland's obesity problem is well publicised and the increased incidence of IIH provides further evidence of the significant adverse health implications we are starting to see as a consequence.

\section{References}

1. Friedman DI, Jacobson DM. Diagnostic criteria for idiopathic intracranial hypertension. Neurology 2002; 59: 1492-1495.

2. Dhungana S, Sharrack B, Woodroofe N. Idiopathic intracranial hypertension. Acta Neurol Scand 2010; 121: 71-82.

3. Best J, Silvestri G, BJ, Foot B, Atchison J. The Incidence of Blindness Due to Idiopathic Intracranial Hypertension in the UK. Open Ophthalmol J. 2013; 7: 26-29

4. Wall M, Falardeau J, Fletcher WA et al. Risk factors for poor visual outcome in patients with idiopathic intracranial hypertension. Neurology. 2015 Sep 1;85(9):799805.

5. Ireland B, Corbett JJ, Wallace RB. The search for causes of idiopathic intracranial hypertension. A preliminary case-control study. Arch Neurol 1990;47:315-20.

6. Giuseffi V, Wall M, Siegel PZ, Rojas PB. Symptoms and disease associations in idiopathic intracranial hypertension (pseudotumor cerebri): a case-control study. Neurology 1991;41:239-44.

7. Rowe FJ, Sarkies NJ. The relationship between obesity and idiopathic intracranial hypertension. Int J Obes Relat Metab Disord 1999;23:54-9.

8. Galvin JA, Van Stavern GP. Clinical characterization of idiopathic intracranial hypertension at Detroit Medical Centre. J Neurol Sci 2004;223:157-60. 
9. The Scottish Government. The Scottish Health Survey 2012 - Obesity.. http://www.gov.scot/Publications/2013/09/3684 - last accessed 4/11/15

10. NHS Fife. The annual report of the director of public health, 2012. http://publications.1fife.org.uk/weborgs/nhs/uploadfiles/publications/c64_DirectorofP ublicHealthAnnualReportversion-final.doc - last accessed 4/11/15

11. Durcan FJ, Corbett JJ, Wall M. The incidence of pseudotumour cerebri. Population studies in Iowa and Louisiana. Arch Neurol 1988; 45: 875-877

12. Radhakrishnan K, Ahlskog JE, Cross SA, Kurland LT, O'Fallon WM. Idiopathic intracranial hypertension (pseudotumour cerebri): descriptive epidemiology in Rochester, Minn. 1976 to 1990. Arch Neurol 1993; 50: 78-80

13. Craig JJ, Mulholland DA, Gibson JM. Idiopathic intracranial hypertension; incidence, presenting features and outcome in Northern Ireland (1991-1995). Ulster Med J 2001; 70: 31-35

14. Kesler A, Goldhammer Y, Gadoth N. Do men with pseudotumor cerebri share the same characterstics as women? A retrospective review of 141 cases. $J$ Neuroophthalmol 2001;21:15-7

15. World Health Organisation. Global Health Observatory (GHO) data. http://www.who.int/gho/ncd/risk_factors/obesity_text/en/ - last accessed 4/11/15 16. Ang GS, Ng WS \& Azuara-Blanco A. The influence of the new general ophthalmic services (GOS) contract in optometrist referrals for glaucoma in Scotland. Eye 2009; 23: 351-355

17. Corbett JJ, Savino PJ, Thompson HS. Visual loss in pseudotumor cerebr: followup of 57 patients from five to 41 years and a profile of 14 patients with permanent severe visual loss. Arch Neurol. 1982;39:461-74. 
18. Ball AK. Idiopathic Intracranial Hypertension: A thesis submitted to the University of Birmingham. University of Birmingham research archive 2009. http://etheses.bham.ac.uk/757/1/Ball_10MD.pdf - last accessed 4/11/15

19. McGirt MJ, Woodworth G, Thomas G, Miller N, Williams M, Rigamonti D. Cerebrospinal fluid shunt placement for pseudotumour cerebri-assosciated intractable headache: predictors of treatment and response and an analysis of long-term outcomes. J Neurosurg. 2004 Oct;101(4):627-32

20. Sinclair A, Burdon M, Ball A, et al . Low energy diet and intracranial pressure in women with idiopathic intracranial hypertension: prospective cohort study. $B M J$ $2010 ; 7: 341$

21. Sugerman, H. J., W. L. Felton, 3rd, et al. (1999). "Gastric surgery for pseudotumor cerebri associated with severe obesity." Annals of Surgery 229(5): 63440; discussion 640-2

22. Chen J, Wall M. Epidemiology and risk factors for Idiopathic Intracranial Hypertension. Int Ophthalmol Clin. 2014; 54(1)

Table 1

\begin{tabular}{|l|}
\hline $\begin{array}{l}\text { Modified Dandy Diagnostic Criteria of Idiopathic Intracranial Hypertension } \\
\text { (Friedman and Jacobson, 2002) }\end{array}$ \\
\hline Signs and symptoms (if present) of increased intracranial pressure \\
\hline Intracranial pressure, as measured in the lateral decubitus position, is elevated \\
\hline The composition of the cerebrospinal fluid is normal \\
\hline There is no evidence of hydrocephalus, mass, structural or vascular lesion \\
\hline No other cause of intracranial hypertension has been identified \\
\hline
\end{tabular}


Table 2: Published studies showing the incidence of IIH in different populations (all significantly lower than shown in this current study).

\begin{tabular}{|c|c|c|c|c|}
\hline Year & Location & Author & Population size & $\begin{array}{l}\text { IIH Incidence } \\
\text { per } 100,000\end{array}$ \\
\hline 1988 & Iowa, USA & Durcan et al & $2,913,808$ & 0.9 \\
\hline 1988 & $\begin{array}{l}\text { Louisiana, } \\
\text { USA }\end{array}$ & Durcan et al & $4,480,681$ & 1.07 \\
\hline 1993 & $\begin{array}{l}\text { Benghazi, } \\
\text { Libya }\end{array}$ & $\begin{array}{l}\text { Radhakrishnan } \\
\text { et al }\end{array}$ & 519,000 & 2.2 \\
\hline 2000 & $\begin{array}{l}\text { Hokkaido, } \\
\text { Japan }\end{array}$ & Yabe et al & $5,780,000$ & 0.03 \\
\hline 2001 & $\begin{array}{l}\text { Belfast, } \mathrm{N} \\
\text { Ireland }\end{array}$ & Craig et al & $1,640,000$ & 0.6 \\
\hline 2001 & Israel & Kesler et al & $5,970,000$ & 0.75 \\
\hline 2004 & Parma, Italy & Carta et al & unknown & 0.28 \\
\hline 2011 & Sheffield & Raoof et al & 513,234 & 1.56 \\
\hline 2014 & Fife & Current Study & 365,000 & 3.56 \\
\hline
\end{tabular}

